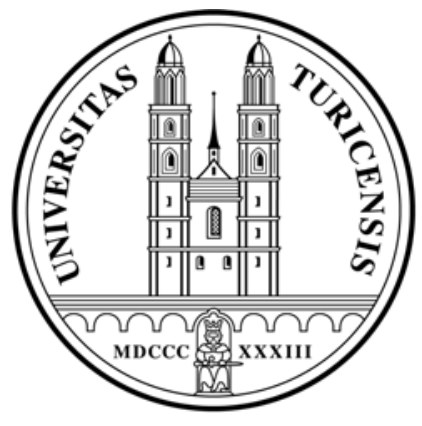

Institute for Empirical Research in Economics

University of Zurich

Working Paper Series

ISSN 1424-0459

Working Paper No. 372

\title{
Outside Versus Inside Bonds
}

Aleksander Berentsen and Christopher Waller

May 2008 


\title{
Outside Versus Inside Bonds*
}

\author{
Aleksander Berentsen \\ University of Basel
}

\author{
Christopher Waller \\ University of Notre Dame
}

May 15, 2008

\begin{abstract}
When agents are liquidity constrained, two options exist - borrow or sell assets. We compare the welfare properties of these options in two economies: in one, agents can borrow (issue inside bonds) and in the other they can sell government bonds (outside bonds). All transactions are voluntary, implying no taxation or forced redemption of private debt. We show that any allocation in the economy with inside bonds can be replicated in the economy with outside bonds and that the converse is not true. Moreover, under best policies, the allocation with outside bonds strictly Pareto dominates the allocation with inside bonds.
\end{abstract}

JEL-Code: E4, E5

Key-Words: Liquidity, Financial markets, Monetary policy, Search

${ }^{*}$ The paper has benefitted from comments by Narayana Kocherlakota, Neil Wallace, Randy Wright and participants at several seminar and conference presentations. We thank the Federal Reserve Bank of Cleveland, and the Kellogg Institute at the University of Notre Dame for research support. 


\section{Introduction}

In monetary economies, agents often face binding liquidity constraints. In such situations, they can acquire additional liquidity by borrowing or selling assets. Several papers have studied the case where agents can sell nominal government bonds (outside bonds) for money while others allow agents to borrow money (issue inside bonds). ${ }^{1}$ These different methods for relaxing liquidity constraints raise the following questions: First, following the logic of Modigliani-Miller, do these alternative arrangements lead to equivalent allocations? Second, what is the optimal monetary policy in each case? Third, under optimal policies, is one preferred to another? Our focus in this paper is to address these questions.

Within a common monetary framework, we consider two economies: one in which agents trade government bonds and one in which they trade inside bonds. We first show that for any positive inflation rate, bond trades improve the allocation in both economies. ${ }^{2}$ With regard to the first question, for sufficiently high inflation rates, we find that a Modigliani-Miller type result holds - the allocations in the two economies are the same. With regard to the second question, the optimal policy for the inside bond economy involves a strictly positive rate of inflation while in the outside bond economy the optimal policy requires the bonds/money ratio and the inflation rate to be arbitrarily close to zero. Finally, under the optimal policies, the allocation with outside bonds generates higher welfare than the allocation with inside bonds.

We prove these results in a general equilibrium monetary model in the spirit of Lagos and Wright (2005) with fiat money and one-period bonds. As in Kocherlakota (2003), to make a fair comparison across economies we assume that all trades must be voluntary. ${ }^{3}$ This implies that the government cannot use lump-sum taxes to redeem outstanding government debt and that, in the inside bond economy, redemption of inside bonds must be voluntary. Our results suggest a direct link between Modigliani-Miller type equivalence results and the ability to collect taxes and/or debt.

\footnotetext{
${ }^{1}$ Examples of the first method include Kocherlakota (2003), Shi (2005, 2007), Boel and Camera (2007) and Marchesi and Senesi (2007). Examples of the latter include Aiyagari and Williamson (2000), Aykol (2004), Berentsen, Camera and Waller (2007), and Diaz and Perrera-Tallo (2007).

${ }^{2}$ The basic mechanism for improving the allocation in both models is the same - agents are able to trade idle cash balances for interest bearing assets. This raises the demand for money and thus its real value in equilibrium.

${ }^{3}$ In a recent paper, Kocherlakota (2007) emphasizes that many results in the literature rely on asymmetric collection powers of private and government entities. To eliminate this asymmetry, he assumes equal and positive collection powers for both type of agents. We eliminate it by assuming that neither has any collection power. With this assumption we are ensuring that any differences in allocations that arise are not the result of inherent differences in the collection powers across public and private entities.
} 
Under optimal policies, the allocations are equivalent in the two economies if the constraint on the ability to collect debt in the inside bond economy does not bind.

Our equivalence result for high inflation economies is reminiscent of Wallace's (1981) ModiglianiMiller type result for open market operations. In an overlapping generation model, Wallace shows that the composition of a government's debt portfolio - consisting of fiat money and capital does not affect the equilibrium allocation. An crucial element for proving his result is that the government has access to lump-sum taxation. Our equivalence result is also related to a recent paper by Kocherlakota (2007). He considers various models of asset trade. In these models, agents can trade a privately issued one-period bond, a publicly issued one-period bond, or a publicly issued money. He proves that the allocations for these economies are equivalent. ${ }^{4}$ As noted by Kocherlakota, it is crucial for these results to hold that the government has access to lump-sum taxes and private lenders can force some repayment of loans. The same is true in our model, if the government has access to lump-sum taxation and private lenders can force repayment, then given an equilibrium in one of these economies, it is possible to pick policy in the other economy that generates an outcome-equivalent equilibrium. ${ }^{5}$

Several further papers are related to what we do here. Kehoe and Levine (2001) compare allocations in a dynamic economy when agents can acquire consumption goods in one case by selling their capital holdings and in another case by issuing debt subject to a borrowing constraint. They show that if agents are sufficiently patient, the allocations are the same in a deterministic environment, but if they are sufficiently impatient, then the debt constrained allocation leads to a better allocation. However, they study trade in real assets while we analyze trade in nominal assets. Furthermore, they do not examine government policy in their economies whereas we do. Shi (2007) examines the implications of illiquid bonds in a monetary search model where there are legal restrictions preventing bonds from being used as a medium of exchange in some transactions but not in others. The legal restrictions make outside bonds illiquid relative to money. He finds that having illiquid bonds can be welfare improving. In Boel and Camera (2006), bonds are illiquid in the sense that there is a transaction fee for converting them into cash. Since agents have different discount factors and trading opportunities, for some parameter configurations, there is a welfare improving

\footnotetext{
${ }^{4}$ In an earlier paper, Taub (1994) derived a related equivalence result between money and credit.

${ }^{5}$ In Kocherlakota's model money plays no transaction role. In contrast, we show that this equivalence result holds when money is a medium of exchange and bonds are not.
} 
role for illiquid bonds under the optimal monetary policy. Marchesiani and Senesi (2007) consider an economy where agents with idle money holdings can buy illiquid outside bonds. The government finances the interest payment through lump-sum taxes. They show that the opportunity to buy interest bearing bonds is strictly welfare improving because it allows agents with idle money to save. Lagos and Rocheteau (2003) study the use of illiquid bonds in a variant of the Lagos-Wright model. They find that under the optimal monetary policy (zero inflation) illiquid bonds are inessential. ${ }^{6}$ Finally, the paper is also related to Cavalcanti and Wallace (1999a, 1999b), who study the relation between inside and outside money. Their model is related to ours since some buyers are able to relax their cash constraint by issuing personal liabilities to sellers which improves the allocation.

The structure of the paper is as follows. In Section 2, we describe the environment. Section 3 contains an analysis of the economy with outside bonds. Section 4 examines the economy with inside bonds, and Section 5 compares the allocations of the two economies. Section 6 concludes. All proofs are in the Appendix.

\section{The environment}

The basic framework we use is the divisible money model developed in Lagos and Wright (2005). This model is useful because it allows us to introduce heterogeneous preferences for consumption and production while still keeping the distribution of money balances analytically tractable. ${ }^{7}$ Time is discrete, and in each period there are three perfectly competitive markets that open sequentially. There is a $[0,1]$ continuum of infinitely-lived agents and one perishable good produced and consumed by all agents.

The timing of the model is as follows. The first market is a financial market where agents trade money for bonds as in Berentsen, Camera and Waller (2007). The second market is a goods market where agents trade money for market 2 goods. In the third market, all agents can produce and consume market 3 goods and readjust their portfolios.

At the beginning of the first market, agents get a preference shock that determines whether

\footnotetext{
${ }^{6}$ Furthermore, there are a number of papers that study the coexistence of money and bonds (e.g. Diaz-PerreraTallo (2007), Ferris and Watanabe (2007), Sun (2007), and Telyukova and Wright (2007)). The key difference to our work is that they never compare the allocative effects of different bonds.

${ }^{7}$ An alternative framework would be Shi (1997) which we could amend with preference and technology shocks to generate the same results.
} 
they can produce or consume in the second market. With probability $1-n$, an agent can consume and cannot produce. We refer to these agents as buyers. With probability $n$, an agent can produce and cannot consume. These are sellers. Moreover, buyers receive an idiosyncratic preference shock to utility. They also learn that they will get utility $\varepsilon u(q)$ from $q$ consumption in the second market, where $u^{\prime}(q),-u^{\prime \prime}(q)>0$. The shock $\varepsilon$ has a continuous distribution $F(\varepsilon)$ with support $\left[0, \varepsilon_{H}\right]$, is iid across buyers, serially uncorrelated and has the expected value $\bar{\varepsilon}=\int_{0}^{\varepsilon_{H}} \varepsilon d F(\varepsilon) .{ }^{8}$ Producers in the second market incur a utility cost $c(q)=q$ from producing $q$ units of output. All trades in market 2 are anonymous, and agents' trading histories in this market are private information, thus no trade credit exists. Hence, there is a role for money, as sellers require immediate compensation for their production effort.

Following Lagos and Wright (2005), we assume that agents receive utility $U(x)$ from $x$ consumption, with $U^{\prime}(x),-U^{\prime \prime}(x)>0, U^{\prime}(0)=\infty$, and $U^{\prime}(+\infty)=0$. They can also produce these goods with a constant returns to scale production technology where one unit of the consumption good is produced with one unit of labor $h$ generating one unit of disutility. ${ }^{9}$ The discount factor across periods is $\beta$.

\subsection{First-best allocation}

The expected steady state lifetime utility of the representative agent at the beginning of the period before types are realized is

$$
(1-\beta) \mathcal{W}=\int_{0}^{\varepsilon_{H}}\left[(1-n) \varepsilon u\left(q_{\varepsilon}\right)-n q_{s}\right] d F(\varepsilon)+U(x)-h .
$$

where $q_{\varepsilon}$ is consumption and $q_{s}$ production in market 2 . We use (1) as our welfare criteria.

To derive the welfare maximizing quantities, we assume that all agents are treated symmetrically. The planner then maximizes (1) subject to the feasibility constraint

$$
Q \equiv(1-n) \int_{0}^{\varepsilon_{H}} q_{\varepsilon} d F(\varepsilon)=n q_{s}
$$

\footnotetext{
${ }^{8}$ All of our results go through with a non-zero lower bound. Setting the lower bound of $\varepsilon$ to zero simplifies the presentation of the results.

${ }^{9}$ As in Lagos and Wright (2005), these assumptions allow us to get a degenerate distribution of money holdings at the beginning of a period. The different utility functions $U($.$) and u($.$) allow us to impose technical conditions$ such that in equilibrium all agents produce and consume in the last market.
} 
where $Q$ is aggregate consumption. The first-best allocation satisfies

$$
\begin{aligned}
U^{\prime}\left(x^{*}\right) & =1 \text { and } \\
\varepsilon u^{\prime}\left[q^{*}(\varepsilon)\right] & =1 \text { for all } \varepsilon .
\end{aligned}
$$

These are the quantities chosen by a social planner who could force agents to produce and consume.

\subsection{Outside bonds versus inside bonds}

We analyze equilibria of the model under two different bond markets - a market for outside bonds and one for inside bonds. Outside bonds are nominal government debt obligations, whereas inside bonds are private debt obligations. We assume that the government has a record-keeping technology over bond trades and acts as the intermediary in the bond market. Bond holdings are book-keeping entries - no physical object exists. This makes bonds incapable of being used as media of exchange in market 2, hence they are illiquid as in Kocherlakota (2003). An alternative would be to assume a legal restriction exists on the use of outside bonds as media of exchange. The government has no record-keeping technology over goods trades. Since agents are anonymous in market 2, a buyer's promise to deliver outside bonds to a seller in market 3 is not credible. Consequently, fiat money is essential for trade in market 2 .

Inside bonds are financial claims on private agents, issued in a private bond market. Consequently, issuing inside bonds is equivalent to receiving credit as in Berentsen, Camera and Waller (2007). We assume that a perfectly competitive financial market exists where intermediaries have a record-keeping technology over financial trades. The intermediaries acquire nominal debt obligations from borrowers and issue nominal debt obligations on themselves to depositors, which are securitized by their acquired claims. Private agents are still anonymous to each other but not to the financial intermediary. ${ }^{10}$ No record-keeping technology exists in the goods market, thus ruling out trade credit between buyers and sellers in market 2 .

In any model of credit, default is a serious issue. We consider an environment where repayment is voluntary - creditors have no powers to collect unpaid debts. For an agent, unpaid debt has

\footnotetext{
${ }^{10}$ An example is a bank that accepts nominal deposits and makes nominal loans. While the bank knows who it trades with, borrowers do not know the identity of depositors and vice versa.
} 
two consequences. First, he receives no further loans unless the debt is repaid. Second, he cannot save by acquiring nominal debt obligations from the financial intermediary, unless he repays any outstanding debt. Given these rules, we derive conditions to ensure voluntary redemption and show that this may involve binding borrowing constraints, i.e., credit rationing. We assume the financial intermediaries honor their debt obligations.

\subsection{Government}

In the model with outside bonds, we assume a government exists that controls the supply of fiat currency and issues one-period nominal non-tangible bonds. These bonds are perfectly divisible, payable to the bearer and default free. ${ }^{11}$ One bond pays off one unit of currency at maturity. Denote $M_{t}$ as the per capita money stock and $B_{t}$ as the per capita stock of newly issued bonds at the end of period $t$. The change in the money stock is given by

$$
M_{t}-M_{t-1}=\tau_{t} M_{t-1}+B_{t-1}-\rho_{t} B_{t}+P_{t} G_{t}
$$

where $P_{t} G_{t}$ is the nominal amount of government spending in period $t$ in the centralized market, and $P_{t}$ is the money price of goods in market $3 .{ }^{12}$ The total change in the money stock is comprised of three components: first, a lump-sum transfer of cash (a 'gift' of cash); second, the net difference between the cash created to redeem bonds, $B_{t-1}$, and the net cash withdrawal from selling $B_{t}$ units of bonds at the price $\rho_{t}$; and finally, the cash printed to pay for government goods. We assume there are positive initial stocks of money and outside bonds $M_{0}$ and $B_{0}$. For $\tau_{t}<0$, the government must be able to extract money via lump-sum taxes from the economy. Throughout the paper, we assume that $\tau_{t}<0$ is not feasible because, as for the private sector, the government has no collection power. ${ }^{13}$

To simplify the analysis, we assume $G_{t}=0$ for all $t$. This implies that all money creation comes from paying off net nominal bond obligations $B_{t-1}-\rho_{t} B_{t}$ and the lump-sum gifts of money $\tau_{t} M_{t-1}$.

\footnotetext{
${ }^{11}$ The government has no incentive to default since it redeems its bonds by printing money at no cost.

${ }^{12}$ Although (4) looks like the standard government budget constraint, it is not since $\tau_{t} M_{t-1}>0$ is a lump-sum gift of cash that is not used to finance government spending.

${ }^{13}$ The inability to impose lump-sum taxes occurs in environments with limited enforcement. In such environments, all trades must be voluntary, and so lump-sum taxes of money are not feasible because the government cannot impose any penalties on the agents. If it could impose such penalties, there would be no role for money since "producers could be forced to produce for households" (Kocherlakota 2003, p. 185).
} 
For the case of outside bonds, we assume that $\tau_{t}=0 .{ }^{14}$ Consequently, (4) reduces to

$$
M_{t}-M_{t-1}=B_{t-1}-\rho_{t} B_{t}
$$

This allows us to focus solely on how 'open market operations' affect the equilibrium allocation and allows us to ignore optimal taxation issues on financing government spending. By dividing (5) by $B_{t-1}$, we express the government budget constraint in term of the ratio of money to bonds as follows

$$
\left(\gamma_{t}-1\right) \frac{M_{t-1}}{B_{t-1}}=1-\rho_{t} \eta_{t}
$$

where $\eta_{t} \equiv B_{t} / B_{t-1}$ is the gross growth rate of bonds and where $\gamma_{t} \equiv M_{t} / M_{t-1}$ is the gross growth rate of money. This equation relates the gross growth rate of money $\gamma_{t}$ to the gross growth rate of bonds $\eta_{t}$.

In the model with inside bonds, we assume that $B_{t}=0$ in all periods, but the government still controls the amount of fiat currency in the economy. In this case, agents receive lump-sum gifts of money $\tau_{t} M_{t-1} \geq 0$, and the money supply grows according to $M_{t}=\left(1+\tau_{t}\right) M_{t-1}=\gamma_{t} M_{t-1}$.

\subsection{Stationary equilibria}

In period $t$, let $\phi_{t}=1 / P_{t}$ be the real price of money in market 3 . For notational ease, variables corresponding to the next period are indexed by +1 , and variables corresponding to the previous period are indexed by -1 . We focus on symmetric and stationary monetary equilibria where all agents follow identical strategies and where real allocations are constant over time. In a stationary equilibrium, end-of-period real money balances are time-invariant

$$
\phi M=\phi_{+1} M_{+1} .
$$

Moreover, we restrict our attention to equilibria where $\gamma$ is time invariant which implies that $\phi / \phi_{+1}=P_{+1} / P=M_{+1} / M=\gamma$.

\footnotetext{
${ }^{14}$ All our results continue to hold for $\tau_{t}>0$. The case $\tau_{t}<0$ is not feasible. See the previous footnote.
} 


\section{Outside bonds}

In this section, we analyze the economy with outside bonds. Let $V(m, b)$ be the expected value from entering market 3 with $m$ and $b$ units of fiat money and nominal bonds. Let $q_{\varepsilon}$ denote the quantities consumed by a type $\varepsilon$ buyer, and $q_{s}$ the quantity produced by a seller trading in market 2. Let $y_{j}$ denote the quantity of outside bonds bought by an agent of type $j=\varepsilon, s$ in market 1 . The goods price of money in market 3 is $\phi$ while $p$ is the money price of goods in market 2 . Let $a$ be the price of bonds in market 1 , consequently the nominal interest rate earned by acquiring a bond in this market is $i=(1-a) / a$, which is greater than zero if and only if $a<1$. For notational convenience we suppress the dependence of the value functions on time.

In the third market, the problem of a representative agent in period $t$ is:

$$
\begin{aligned}
V(m, b)= & \max _{x, h, m^{\prime}, b^{\prime}, q_{\varepsilon}^{\prime}, q_{s}^{\prime}, y_{\varepsilon}^{\prime}, y_{s}^{\prime}} U(x)-h \\
& +\beta(1-n) \int_{0}^{\varepsilon_{H}}\left[\varepsilon u\left(q_{\varepsilon}^{\prime}\right)+V\left(m^{\prime}-a^{\prime} y_{\varepsilon}^{\prime}-p^{\prime} q_{\varepsilon}^{\prime}, b^{\prime}+y_{\varepsilon}^{\prime}\right)\right] d F(\varepsilon) \\
& +\beta n\left[-q_{s}^{\prime}+V\left(m^{\prime}-a^{\prime} y_{s}^{\prime}+p^{\prime} q_{s}^{\prime}, b^{\prime}+y_{s}^{\prime}\right)\right]
\end{aligned}
$$

subject to the sequence of constraints

$$
\begin{gathered}
x+\phi m^{\prime}+\phi \rho b^{\prime}=h+\phi m+\phi b \\
p q_{\varepsilon} \leq m-a y_{\varepsilon} \quad 0 \leq m-a y_{j} \quad 0 \leq b+y_{j}
\end{gathered}
$$

where the primes denote next period values. The first constraint is the budget constraint in market 3 while the second is the cash constraint for purchasing goods in market 2 . The last two are short-selling constraints on money and bonds in market 1.

The envelope conditions for this problem are

$$
V_{m}=\phi ; V_{b}=\phi .
$$


The solution to this problem yields the following pricing relationships

$$
\begin{aligned}
p & =1 / \phi \\
\rho_{-1} & =a=(1+i)^{-1} .
\end{aligned}
$$

The first equation is simply an arbitrage condition for a seller - he can produce a unit of goods and sell it for $p$ units of money in market 2 or for $1 / \phi$ units of money in market 3 . Since his cost of production are linear, on the margin he must be indifferent between producing in either market. The second equation arises because there is no aggregate uncertainty as to how many buyers and sellers there are in market 1 . Consequently, arbitrage implies that the bond price has to be the same between market 3 and market 1 in period +1 .

With regards to consumption, we get $U^{\prime}(x)=1$ while there is a critical value for the taste index $\tilde{\varepsilon}$ such that

$$
\tilde{\varepsilon} u^{\prime}(\tilde{q})=1+i
$$

This critical buyer sells all of his bonds and spends all of money balances to acquire $\tilde{q}$ units of goods. Because a buyer's desired consumption is increasing in $\varepsilon$, it then follows that buyers with $\varepsilon \geq \tilde{\varepsilon}$ also sell all their bonds and consume

$$
\tilde{q}=\phi m+\phi b /(1+i) .
$$

On the other hand, buyers with $\varepsilon \leq \tilde{\varepsilon}$, either sell a portion of their bonds or, as is the case for buyers with very low $\varepsilon$, buy additional bonds with some of their cash. Accordingly, a market 2 buyer's consumption satisfies

$$
q_{\varepsilon}=\left\{\begin{array}{lll}
u^{\prime-1}[(1+i) / \varepsilon] & \text { if } & \varepsilon \leq \tilde{\varepsilon} \\
u^{\prime-1}[(1+i) / \tilde{\varepsilon}] & \text { if } & \varepsilon \geq \tilde{\varepsilon}
\end{array}\right.
$$

With regards to market 2 production, due to linearity of the cost function and the arbitrage condition (9) sellers are indifferent as to how much they sell in market 2. Since we focus on a symmetric equilibrium, we assume that all sellers produce the same amount. 
Given these consumption choices and the pricing conditions, we get the following bond demands:

$$
\begin{aligned}
& y_{s} \in[-b, m(1+i)] \quad \text { if } \quad i=0 \\
& y_{s}=m(1+i) \quad \text { if } \quad i>0 \\
& y_{\varepsilon} \in[-b, m(1+i)] \quad \text { if } \quad \varepsilon u^{\prime}\left(q_{\varepsilon}\right)=1+i \\
& y_{\varepsilon}=-b \quad \text { if } \varepsilon u^{\prime}(\tilde{q})>1+i \text {. }
\end{aligned}
$$

Agents who know they will be sellers in market 2 sell all of their money for bonds if $i>0$ while those who will be buyers alter their bond holdings depending on the intensity of their desired consumption.

Finally, the first-order condition for $m^{\prime}$ can be written as

$$
\phi=\beta \phi^{\prime}\left\{(1-n) \int_{0}^{\varepsilon_{H}} \varepsilon u^{\prime}\left(q_{\varepsilon}^{\prime}\right) d F(\varepsilon)+n\left(1+i^{\prime}\right)\right\} .
$$

The cost of acquiring an additional unit of money today is $\phi$ units of goods which requires incurring $\phi$ units of disutility from acquiring those goods. The expected future benefit from this additional unit of money is its expected marginal utility from consuming extra goods as a buyer or from trading it for bonds and earning $1+i^{\prime}$ units of money or $\phi^{\prime}\left(1+i^{\prime}\right)$ units of utility next period.

\subsection{Equilibrium}

A symmetric stationary monetary equilibrium consists of the agent's decisions which meet the following requirements: (i) The decisions solve the maximization problems specified above; (ii) The decisions are symmetric across all agents with the same preference shocks; (iii) The goods and bond markets clear. The last part requires (2) and

$$
n y_{s}+(1-n) \int_{0}^{\varepsilon_{H}} y_{\varepsilon} d F(\varepsilon)=0
$$

to hold.

We now derive the symmetric stationary equilibrium allocation. In any symmetric equilibrium, where money and bonds have positive values $m^{\prime}=M$ and $b^{\prime}=B$. In a stationary equilibrium, 
using (11) and (13) we can write (16) as

$$
\frac{\gamma-\beta(1+i)}{\beta(1+i)}=(1-n) \int_{\tilde{\varepsilon}}^{\varepsilon_{H}}\left(\frac{\varepsilon}{\tilde{\varepsilon}}-1\right) d F(\varepsilon)
$$

This is an equation in $i$ and $\tilde{\varepsilon}$. We now derive a second equation $i$ and $\tilde{\varepsilon}$ which we can then use to define the equilibrium.

In any stationary equilibrium, $a$ is constant so $a=1 /(1+i)=\rho$. We focus on equilibria where the stocks of bonds $B$ and money $M$ grow at the same rate $\gamma \cdot{ }^{15}$ We can then rewrite the government budget constraint (5) to solve for $1+i$ as a function of $\gamma$ and $M_{-1} / B_{-1}$

$$
1+i=\frac{\gamma}{1-(\gamma-1) M_{-1} / B_{-1}}
$$

Since $B$ and $M$ grow at the same rate, we have $M_{-1} / B_{-1}=M / B=M_{0} / B_{0}$ for all $t .{ }^{16}$ A nonnegative nominal interest rate requires the denominator of (19) to be positive and the right-hand side of (19) to be greater than or equal to 1 . This requires $B_{0} / M_{0}+1>\gamma \geq 1$. Thus, for a given ratio of nominal outside bonds to outside money, the range of feasible $\gamma$ is bounded by this expression. Define $\bar{\gamma} \equiv 1+B_{0} / M_{0}$. If $\gamma=1$, then $i=0$. Substitute (19) into (11) and (18) to get

$$
\begin{aligned}
\tilde{\varepsilon} u^{\prime}(\tilde{q}) & =\frac{\gamma}{1-(\gamma-1) M_{0} / B_{0}} \\
1-(\gamma-1) M_{0} / B_{0} & =\beta\left[(1-n) \int_{\tilde{\varepsilon}}^{\varepsilon_{H}}\left(\frac{\varepsilon}{\tilde{\varepsilon}}-1\right) d F(\varepsilon)+1\right]
\end{aligned}
$$

For given values of $\gamma$ and $M_{0} / B_{0}$, the second equation pins down $\tilde{\varepsilon}$. The first equation then yields $\tilde{q}$. Given $\tilde{q}$ and $\tilde{\varepsilon}$, we can then solve for all endogenous quantities and prices.

Definition 1 A symmetric stationary monetary equilibrium is an $\tilde{\varepsilon}$ that satisfies (21).

In what follows we define $\gamma_{H} \equiv 1+(1-\beta) B_{0} / M_{0}<\bar{\gamma}$.

Proposition 1 For $1 \leq \gamma<\bar{\gamma}$, a unique symmetric stationary monetary equilibrium exists. If $\gamma \leq \gamma_{H}$, then $\tilde{\varepsilon} \in\left(0, \varepsilon_{H}\right]$. If $\gamma_{H}<\gamma<\bar{\gamma}$, then $\tilde{\varepsilon}>\varepsilon_{H}$.

\footnotetext{
${ }^{15}$ We have also explored the case where bonds and money grow at different rates. In this case a stationary equilibrium requires lump-sum injections of money in each period. The real allocations that can be attained are the same as the allocations when money and bonds grow at the same rates.

${ }^{16}$ Since the assets are nominal objects, the government can start the economy off by one-time injections of cash $M_{0}$ and bonds $B_{0}$ to obtain the desired ratio of $M_{0} / B_{0}$.
} 
The essence of this proposition is that for sufficiently low inflation rates, high $\varepsilon$ buyers will face binding bond sale constraints, and so $\varepsilon u^{\prime}\left(q_{\varepsilon}\right)>1+i$. In contrast, for sufficiently high inflation rates, no buyers face binding bond sales constraints, implying $\varepsilon u^{\prime}\left(q_{\varepsilon}\right)=1+i$ for all $\varepsilon$, and from (21) we have $1-(\gamma-1) M_{0} / B_{0}=\beta$. Then, from (19), we obtain the Fisher equation

$$
i=\frac{\gamma-\beta}{\beta}
$$

\subsection{Optimal policy}

There are two inefficiencies in this economy that policy must try to overcome. First, when $\tilde{\varepsilon}<\varepsilon_{H}$, there is an inefficient allocation of consumption across buyers since some buyers are constrained while others are not. As a result, the marginal utilities of consumption are not equalized. This is an extensive margin inefficiency. Second, due to the time cost of holding money, the quantities consumed by all buyers are inefficiently low if $\gamma>\beta$. This is an intensive margin inefficiency.

Keeping in mind these two inefficiencies, we now state the optimal policy in the outside bond economy.

Proposition 2 The optimal policy is to set $\gamma=1+(1-\beta) B_{0} / M_{0}$ and then let $B_{0} / M_{0} \rightarrow 0$. Under this policy, the limiting allocation satisfies $\tilde{\varepsilon}=\varepsilon_{H}$ and

$$
\varepsilon u^{\prime}\left(q_{\varepsilon}\right)=1 / \beta \quad \forall \varepsilon
$$

According to Proposition 2, the optimal policy makes $\tilde{\varepsilon}=\varepsilon_{H}$ which equalizes the marginal utility of consumption across all buyers. This requires that the left-hand side of (21) equals $\beta$. Then, using this expression and (20), we get

$$
\varepsilon u^{\prime}\left(q_{\varepsilon}\right)=\gamma / \beta \quad \forall \varepsilon
$$

The optimal policy then requires that $\gamma$ be as small as possible, yet kept above 1 . This can be achieved by letting $B_{0} \rightarrow 0$, implying $\gamma$ is arbitrarily close to one. The intuition for this result is that the government needs to print money to redeem bonds. This generates inflation which has a negative intensive margin effect. By reducing the bonds/money ratio, the amount of newly printed 
money can be reduced while still providing a second asset for portfolio reallocation. In the limit, the nominal interest rate approaches the real interest rate and the inflation rate goes to zero. ${ }^{17}$

One might ask: How can illiquid bonds raise consumption and welfare even though the quantity in the limiting case approaches zero? The key to understand this is that the presence of interestbearing bonds raises the demand for money and hence its value. They increase the value of money because they allow agents, on the margin, to trade idle cash for an interest-bearing asset. Higher valued money allows agents to consume more thereby improving the allocation. Note that this reasoning is valid for any strictly positive stock of bonds in the economy. The size of the nominal bond stock is not relevant for an agent's marginal decision - all that matters is some bonds exist.

An implication of this result is that there is a discrete jump in the allocation at $B=0$, since without bonds consumption and welfare strictly lower than in the limiting equilibrium $B \rightarrow 0$. This is similar to the discrete jump that occurs in monetary models where money serves as a medium of exchange (e.g. Lagos and Wright (2005)). Ignoring barter, if $M=0$ the equilibrium allocation is autarky since no trade occurs. For any $M>0$, however small, the monetary equilibrium allocation strictly dominates the autarky allocation. Here, if $B=0$, there is no other asset and so the allocation equals the allocation in a model where money is the only asset. If we introduce a stock of interest bearing bonds $B>0$, however small, we also get a discrete jump of the allocation if $B$ is not too large.

Figure 1 displays some properties of our model. It displays steady-state welfare in the economy with illiquid bonds as a function of inflation $\gamma$ for several values of the bonds/money ratio. At $\gamma=1$ all welfare levels are equal. The dots correspond to the inflation rates at which the economy switches from being constrained to unconstrained. One can see that moderate inflation rates are welfare improving if the ratio $B_{0} / M_{0}$ is sufficiently small. For large values of $B_{0} / M_{0}$ (e.g. $B_{0} / M_{0}=10$ in Figure 1) it is not welfare improving. For higher values (e.g. $B_{0} / M_{0}=2.5$ ) some inflation is beneficial. In this example, the dots for $B_{0} / M_{0}=0.625,1.25,2.5$ also correspond to the optimal inflation rate for each economy. It is evident that increasing the ratio $B_{0} / M_{0}$ is never welfare increasing. The optimal limiting policy corresponds to dot labelled $B_{0} / M_{0}=0$ at $\gamma=1$. $^{18}$

\footnotetext{
${ }^{17}$ Notice that for any $B \geq 0$ the set of equilibrium allocations is continuous in the rate of inflation.

${ }^{18}$ Figure 1 is drawn for the utility function $u(q)=(1-\alpha)^{-1} q^{1-\alpha}$ with $\alpha=0.5$. We also used a uniform distribution of preference shocks on $[0,2]$ and set the measure of buyers to $n=0.5$ and the discount factor to $\beta=0.95$. We will use the same specification in all figures that follow.
} 
Figure 1: Inflation vs $\mathbf{B}_{0} / \mathbf{M}_{0}$

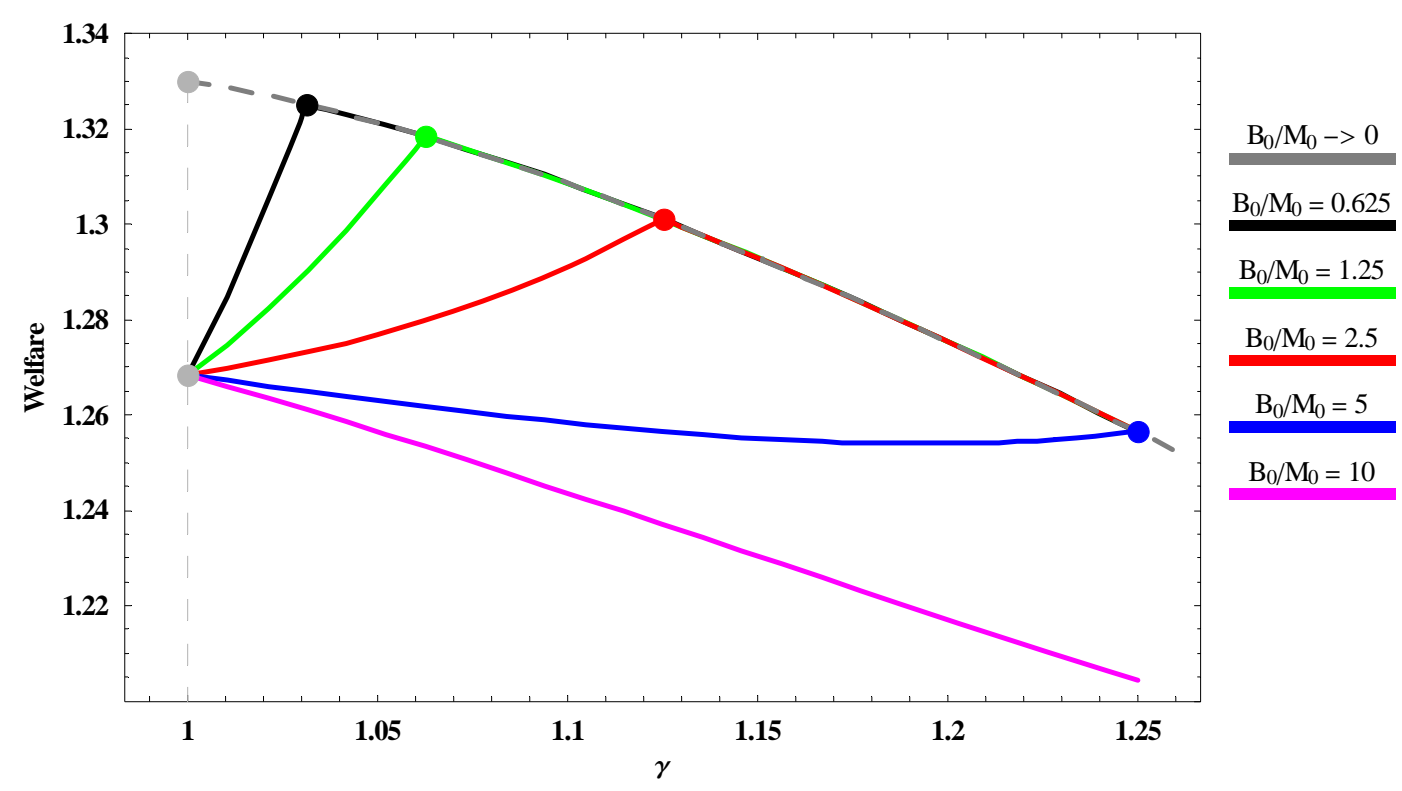

Note that the welfare enhancing-role of illiquid bonds requires a strictly positive nominal interest rate and strictly positive rate of inflation. The reason is that if an agent brings in money and does not need it, he can trade it for an interest-bearing asset that compensates him for bringing 'idle' money into market 1 . This increases the demand for money in market 3 and thus its real value. As a result, there is higher expected consumption in market 2. Thus, illiquid bonds will improve the allocation if $i>0$. However, $i>0$ requires that $\gamma>1$.

Finally, suppose now that instead of book-keeping entries, bonds are tangible objects that can be used as a medium of exchange in market 2, i.e., they are liquid. One can show that in this environment, the allocation is the same as the allocation without bonds. The intuition and proof for this result is straightforward and provided in Kocherlakota (2003, p. 184): "If bonds are as liquid as money, then people will only hold money if nominal interest rates are zero. But then the bonds can just be replaced by money: there is no difference between the two instruments at all." An interesting implication of this result is that "any essentiality of nominal bonds can be traced directly to their (relative) illiquidity (Kocherlakota 2003, p. 184)."19 The same observation is also stated by Hellwig (1993 p. 219) as follows: "if there is an asset whose own rate of return exceeds

\footnotetext{
${ }^{19}$ Alternatively, if nominal bonds are liquid and $i>0$, then the real value of fiat money goes to zero. But since interest on nominal bonds is paid out in units of fiat money, the real value of the interest on bonds has to be zero as well. It then follows that nominal bonds can never be sold at a discount, so $i=0$ is the only equilibrium.
} 
the own rate of return on money in each period with probability one and if this asset has the same marketability properties as fiat money, then there exists no rational expectations equilibrium in which fiat money has a positive real value." Consequently, any model where money and bonds coexist must reduce the marketability properties of bonds relative to fiat money.

\section{Inside Bonds}

In this section, we analyze the model where there are no outside bonds, but inside bonds can be traded in market 1 . In market 1 , sellers and low $\varepsilon$ buyers can use their idle cash balances to acquire nominal bonds from the financial intermediary, which are redeemed in market 3 . High $\varepsilon$ buyers can issue nominal bonds in market 1 to the financial intermediary and redeem them in market 3 . Inside bonds are perfectly divisible, and one inside bond pays off 1 unit of fiat currency in market 3 . Let $b_{j}$ denote the number of inside bonds purchased by an agent of type $j=\varepsilon, s$. When $b_{j}<0$, the agent is borrowing and thus selling inside bonds. Let $a$ denote the market 1 price of these inside bonds. Again, we have $a=(1+i)^{-1} \cdot{ }^{20}$

Again, we focus on symmetric and stationary equilibria where all agents follow identical strategies and where real allocations are constant over time. In a stationary equilibrium, end-of-period real money balances are time-invariant.

In the third market, the problem of a representative agent in period $t$ is:

$$
\begin{aligned}
V(m, b)= & \max _{x, h, m^{\prime}, q_{\varepsilon}^{\prime}, q_{s}^{\prime}, b_{\varepsilon}^{\prime}, b_{s}^{\prime}} U(x)-h \\
& +\beta(1-n) \int_{0}^{\varepsilon_{H}}\left[\varepsilon u\left(q_{\varepsilon}^{\prime}\right)+V\left(m^{\prime}-a^{\prime} b_{\varepsilon}^{\prime}-p^{\prime} q_{\varepsilon}^{\prime}, b_{\varepsilon}^{\prime}\right)\right] d F(\varepsilon) \\
& +\beta n\left[-q_{s}^{\prime}+V\left(m^{\prime}-a^{\prime} b_{s}^{\prime}+p^{\prime} q_{s}^{\prime}, b_{s}^{\prime}\right)\right]
\end{aligned}
$$

subject to the sequence of constraints

$$
\begin{gathered}
x+\phi m^{\prime}=h+\phi m+\phi b_{j} \\
p q_{\varepsilon} \leq m-a b_{\varepsilon} \quad 0 \leq m-a b_{j} \quad-\bar{b} \leq b_{j} .
\end{gathered}
$$

\footnotetext{
${ }^{20}$ One period contracts are optimal here due to the quasi-linearity of preferences. In short, linearity of utility in hours worked means there are no welfare gains from smoothing market 3 labor across time to repay current debt.
} 
The first three constraints are as before. The last constraint is a borrowing constraint where $-\bar{b}$ is the bound on how many inside bonds can be issued. Although the agents take this constraint as exogenous, in equilibrium it is endogenously determined.

As before, the solution to this problems yields (8), (9), (11), (13) and (16). The replacements for (12), (14) and (15) are given by

$$
\begin{aligned}
& \tilde{q}=\phi m+\phi \bar{b} /(1+i) \\
& b_{s} \in[-\bar{b}, m(1+i)] \quad \text { if } \quad i=0 \\
& b_{s}=m(1+i) \quad \text { if } \quad i>0 \\
& b_{\varepsilon} \in[-\bar{b}, m(1+i)] \quad \text { if } \quad \varepsilon u^{\prime}\left(q_{\varepsilon}\right)=1+i \\
& b_{\varepsilon}=-\bar{b} \quad \text { if } \varepsilon u^{\prime}\left(q_{\varepsilon}\right)>1+i .
\end{aligned}
$$

Now the critical buyer spends all of his cash and borrows the maximum but is indifferent to borrowing beyond that point. Buyers with $\varepsilon \leq \tilde{\varepsilon}$, do not issue the maximal amount of inside bonds, whereas borrowers with $\varepsilon \geq \tilde{\varepsilon}$, issue the maximal amount of inside bonds and spend the proceeds on goods.

\subsection{Stationary equilibria}

To derive the symmetric stationary equilibrium, we have to solve for the equilibrium quantities and prices. In any symmetric equilibrium, $m=M_{-1}$. As before (16) reduces to

$$
\frac{\gamma-\beta(1+i)}{\beta(1+i)}=(1-n) \int_{\tilde{\varepsilon}}^{\varepsilon_{H}}\left(\frac{\varepsilon}{\tilde{\varepsilon}}-1\right) d F(\varepsilon)
$$

Comparing (28) to (18), we see that the cutoff values and thus the allocations for the outside bond and inside bond economies will be the same if the nominal interest rate in each economy is the same. Hence, what needs to be determined is whether or not the nominal interest rates will differ across the two economies.

We now derive the value of $\bar{b}$. Since $\bar{b}$ is a nominal variable, what we really want is the real value $\bar{\ell} \equiv \phi \bar{b}$. This quantity is the maximal real amount that an agent is willing to repay in the last 
market. For buyers entering the last market with no money, who redeem their bonds, the expected discounted utility in a steady state is given by (24). A defaulting buyer's expected discounted utility is

$$
\begin{aligned}
\widehat{V}(m, b)= & \max _{\widehat{x}, \widehat{h}_{\varepsilon}, \widehat{m}^{\prime}, \widehat{q}_{\varepsilon}^{\prime}, \widehat{q}_{s}^{\prime}} U(\widehat{x})-\widehat{h}_{\varepsilon} \\
& +\beta(1-n) \int_{0}^{\varepsilon_{H}}\left[\varepsilon u\left(\widehat{q}_{\varepsilon}^{\prime}\right)+V\left(\widehat{m}^{\prime}-p^{\prime} \widehat{q}_{\varepsilon}^{\prime}, 0\right)\right] d F(\varepsilon) \\
& +\beta n\left[-\widehat{q}_{s}^{\prime}+V\left(\widehat{m}^{\prime}+p^{\prime} \widehat{q}_{s}^{\prime}, 0\right)\right]
\end{aligned}
$$

where the hat indicates the optimal choices by a defaulter. The real borrowing constraint makes the agent indifferent between redeeming his bonds or defaulting so that $V(m, b)=\widehat{V}(m, b)$.

When no enforcement exits, agents must voluntarily redeem their bonds. The only punishment for default is permanent exclusion from the inside bond market. Let $\widehat{q}_{\varepsilon}$ denote the quantity purchased by an agent with preference shock $\varepsilon$ who is excluded from the inside bond market. It is straightforward to show that the marginal value of money for a defaulter satisfies

$$
\frac{\gamma-\beta}{\beta}=(1-n) \int_{0}^{\varepsilon_{H}}\left[\varepsilon u^{\prime}\left(\widehat{q}_{\varepsilon}\right)-1\right] d F(\varepsilon)
$$

while (28) continues to determine the value of money for a non-defaulter. Since an agent who defaults can only use the money balances he brings into the period to buy goods, then there is a critical value $\hat{\varepsilon}$ such that

$$
\hat{\varepsilon} u^{\prime}(\widehat{q})=1
$$

His consumption is

$$
\widehat{q}_{\varepsilon}=\left\{\begin{array}{ccc}
q_{\varepsilon}^{*} & \text { if } & \varepsilon \leq \hat{\varepsilon} \\
u^{\prime-1}(1 / \hat{\varepsilon}) & \text { if } & \varepsilon \geq \hat{\varepsilon}
\end{array}\right.
$$

which means that he consumes the first-best quantity $q_{\varepsilon}^{*}$ for $\varepsilon \leq \hat{\varepsilon}$ and the same quantity $u^{\prime-1}(1 / \hat{\varepsilon})$ for all $\varepsilon \geq \hat{\varepsilon}$. The remaining choices, $\widehat{x}$ and $\widehat{h}_{\varepsilon}$ are derived in the Appendix.

Real borrowing constraint Given a borrowing constraint, there are two possibilities: 1) The borrowing constraint is non-binding for all agents or 2) It is binding for some agents. The following 
Lemma is used for the remainder of this section.

Lemma 1 The real borrowing constraint is

$$
\bar{\ell}=\frac{\beta}{(1+i)(1-\beta)}\left[(1-n) \Psi\left(q_{\varepsilon}, \widehat{q}_{\varepsilon}\right)+\left(\frac{\gamma-\beta}{\beta}\right)(\hat{q}-Q)\right]
$$

where

$$
\Psi\left(q_{\varepsilon}, \hat{q}_{\varepsilon}\right)=\int_{0}^{\varepsilon_{H}}\left[\varepsilon u\left(q_{\varepsilon}\right)-q_{\varepsilon}\right] d F(\varepsilon)-\int_{0}^{\varepsilon_{H}}\left[\varepsilon u\left(\hat{q}_{\varepsilon}\right)-\hat{q}_{\varepsilon}\right] d F(\varepsilon) .
$$

and $Q$ is given by (2). We can now define a monetary equilibrium with inside bonds.

Definition 2 A monetary equilibrium with unconstrained borrowing is a set $\left\{q_{\varepsilon}, \widehat{q}_{\varepsilon}, \bar{\ell}, i, \hat{\varepsilon}, \tilde{\varepsilon}\right\}$ satisfying $\tilde{\varepsilon} \geq \varepsilon_{H}$, (13), (31), (32) and

$$
\begin{aligned}
0<\ell_{H} & <\bar{\ell} \\
\frac{\gamma-\beta}{\beta} & =i \\
\frac{\gamma-\beta}{\beta} & =(1-n) \int_{\hat{\varepsilon}}^{\varepsilon_{H}}\left(\frac{\varepsilon}{\hat{\varepsilon}}-1\right) d F(\varepsilon)
\end{aligned}
$$

Equation (34) is obtained by using $\varepsilon u^{\prime}\left(q_{\varepsilon}\right)=1+i$ for all $\varepsilon$ in (28) while (35) comes from combining (29)-(31).

Definition 3 A monetary equilibrium with constrained borrowing is a set $\left\{q_{\varepsilon}, \widehat{q}_{\varepsilon}, \bar{\ell}, i, \hat{\varepsilon}, \tilde{\varepsilon}\right\}$ satisfying (13), (31), (32) and

$$
\begin{aligned}
\bar{\ell} & =u^{\prime-1}[(1+i) / \tilde{\varepsilon}]-Q \\
\frac{\gamma-\beta(1+i)}{\beta(1+i)} & =(1-n) \int_{\tilde{\varepsilon}}^{\varepsilon_{H}}\left(\frac{\varepsilon}{\tilde{\varepsilon}}-1\right) d F(\varepsilon) \\
\frac{\gamma-\beta}{\beta} & =(1-n) \int_{\hat{\varepsilon}}^{\varepsilon_{H}}\left(\frac{\varepsilon}{\hat{\varepsilon}}-1\right) d F(\varepsilon)
\end{aligned}
$$

Since high $\varepsilon$ buyers are credit constrained $\varepsilon u^{\prime}\left(q_{\varepsilon}\right)=1+i$ does not hold for all $\varepsilon$ and (34) no longer holds. It is replaced by equation (36) which is obtained from using the cash constraint of a credit constrained borrower. 
Proposition 3 For a value $\bar{\beta}$, sufficiently close to 1 , if $\beta \in[\bar{\beta}, 1)$, then there is an $\hat{\imath}>0$ such that:

(i) If $i \geq \hat{\imath}$, then a unique monetary equilibrium with unconstrained borrowing exists.

(ii) If $0<i<\hat{\imath}$, then a monetary equilibrium with constrained borrowing may exist.

(iii) If $i=0$ a unique monetary equilibrium without borrowing exists.

Since $i=0$ at $\gamma=1$, inside bonds are not traded and the allocation is the same as the illiquid outside bonds allocation at $i=0$ at $\gamma=1$.

\subsection{Optimal policy}

In an unconstrained borrowing equilibrium, it is straightforward to show that inflation is always welfare reducing since it reduces the real value of money balances and consumption for all agents. However, in a constrained borrowing equilibrium, it may be optimal for the government to set $\gamma>1$. As was the case with outside bonds, at $\gamma=1$ and $i=0$, some buyers consume their firstbest quantities while others do not. Consequently, there is a first-order welfare gain from moving some consumption from those buyers at their first-best quantities to those who are not. In addition to this welfare gain, there is another positive welfare effect from raising $\gamma$ above 1 - it increases the cost of being excluded from the banking system. Since a defaulter carries more money, he pays a higher inflation tax from using cash. By increasing $\gamma$, the punishment for defaulting increases. This relaxes the borrowing constraint and creates a first-order welfare gain. However, the higher inflation reduces real money balances and expected consumption, which lowers welfare. ${ }^{21}$ We can thus state the following:

Proposition 4 In a constrained borrowing equilibrium, if $\beta>\left[1+n+(1-n) \int_{0}^{\tilde{\varepsilon}} d F(\tilde{\varepsilon})\right]^{-1}$, then a positive steady state inflation rate maximizes welfare $\forall \tilde{\varepsilon}$.

Proposition 4 states that the optimal inflation rate is strictly positive if agents are sufficiently patient.

\footnotetext{
${ }^{21}$ Berentsen Camera and Waller (2007) show that for a degenerate distribution for $\varepsilon$, inflation is always welfareincreasing for sufficiently high values of $\beta$. In this section, we extend those results to the case of a non-degenerate distribution of $\varepsilon$.
} 


\section{$5 \quad$ Inside vs outside bonds}

In what follows, we compare the economy with inside bonds to the one with outside bonds. For this comparison, two facts are key. First, at $\gamma=1$, the allocations in both economies are the same. Second, for sufficiently high inflation rates, (22) and (34) are the same so the allocation in an unconstrained borrowing equilibrium is the same as the illiquid outside bond allocation when $\gamma$ is sufficiently high. Thus, differences arise for low inflation rates only.

Proposition 5 Given an equilibrium in the inside bond economy, it is possible to pick policy in the outside bond economy that generates an outcome-equivalent equilibrium. The converse is not true.

The proof of Proposition 5 is as follows. Consider any allocation in the economy with inside

bonds for some $\gamma^{I}$. This allocation is characterized by some interest rate, say $i^{I}$. Choose the same inflation $\gamma=\gamma^{I}$ for the economy with outside bonds and some ratio $B / M$. From (19), this yields some interest rate $i$. Then, by changing $B / M$, one can attain the same interest rate $i=i^{I}$ as in the inside bonds economy. Since $\gamma$ and $i$ are the same in both economies, from (18) and (37), the cutoff values $\tilde{\varepsilon}$ are also the same. It then follows that all quantities $q_{\varepsilon}$ are the same. The converse is not true, since there are allocations in the outside bonds that cannot be attained in the inside bonds economy.

Corollary 1 Under the optimal policies, the allocation with outside bonds Pareto-dominates the inside bond allocation.

Corollary 1 is illustrated in Figure 2. The dashed green line plots steady-state welfare in the outside bonds economy for different values $B_{0} / M_{0}$ when in each case $\gamma$ is chosen optimally. The solid line plots welfare in the inside bonds economy. It is clear that when borrowing constraints are binding (i.e., when $\gamma<\tilde{\gamma}$ ), welfare is strictly lower than in the outside bond economy. 
Figure 2: Outside bonds dominate inside bonds

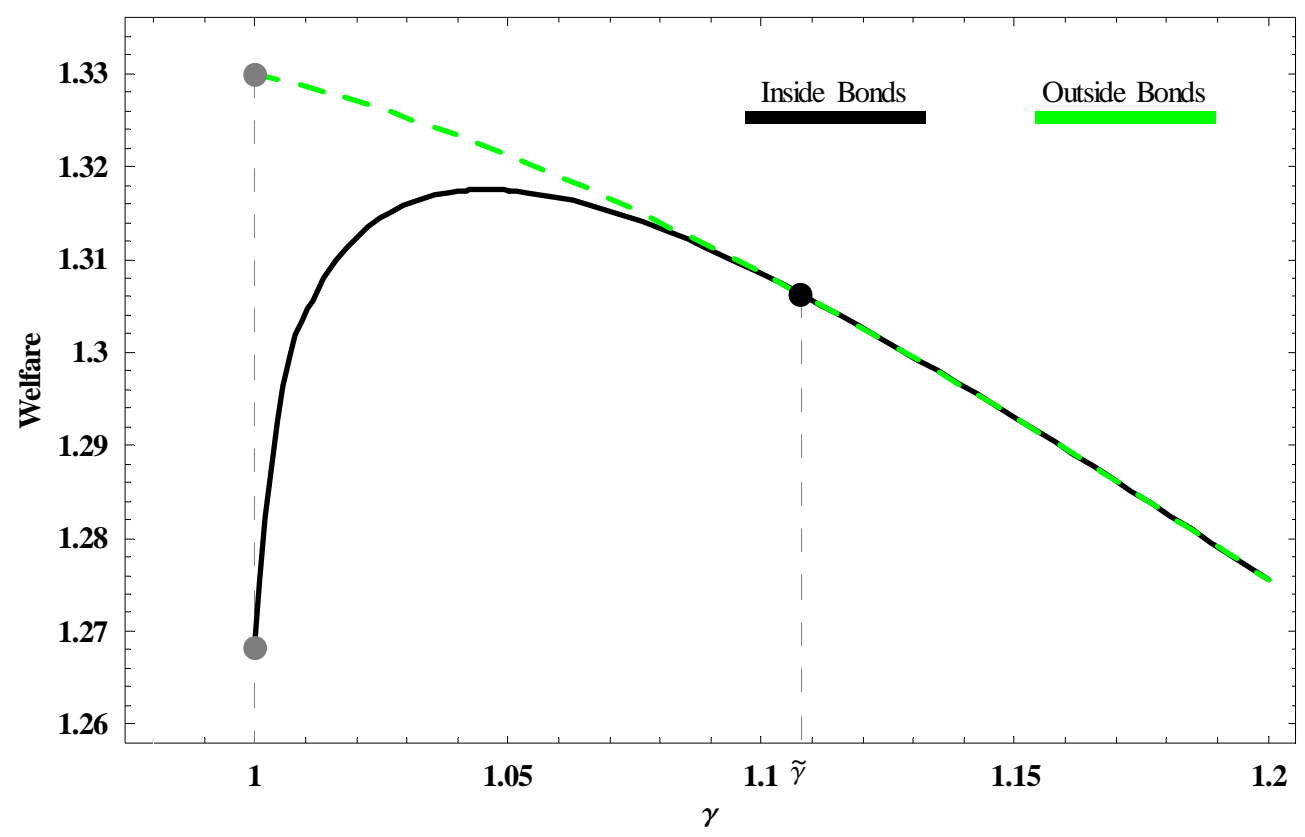

What is the intuition for this result? In the inside bond economy, there is only one instrument, $\gamma$, to solve two inefficiencies - the time cost of holding money (the intensive margin) and the distribution of consumption across agents (extensive margin). Furthermore, $\gamma$ affects the individual decisions to default. In the outside bond economy, the government has two instruments, $\gamma$ and $M_{0} / B_{0}$, to deal with two inefficiencies. However, the key is that individual default is not an issue. In the following section, we show that when enforcement is feasible the allocations are equivalent.

\subsection{Enforcement}

We now depart from one of our main assumptions that all trades must be voluntary. In particular, we assume that in the inside bonds economy redemption of inside bonds can be forced on agents and that the government has access to lump-sum taxes. This allows us to state an equivalence result. When redemption can be forced in the inside bond economy, default is not feasible and so there is no borrowing constraints. It is then straightforward to show that in a stationary equilibrium the 
interest rate and all of the quantities $q_{\varepsilon}$ are determined by ${ }^{22}$

$$
\begin{aligned}
\frac{\gamma-\beta}{\beta} & =i \\
\varepsilon u^{\prime}\left(q_{\varepsilon}\right) & =1+i
\end{aligned}
$$

The first equation comes from the agent's decision of how much money to bring into the period. In equilibrium they are indifferent between acquiring an additional unit of money in the centralized market or borrowing it in the inside bond market. The second equation comes from the buyers' decisions of how much to borrow.

In the Appendix we prove the following

Proposition 6 Assume enforcement is feasible. Then, given an equilibrium in one of these economies, it is possible to pick policy in the other economy that generates an outcome-equivalent equilibrium.

The proof involves showing that if the government can use lump-sum taxes to finance the interest rate on the outstanding stock of bonds, then in a stationary equilibrium the interest rate and all of the quantities $q_{\varepsilon}$ are also determined by (39) and (40). The intuition is that these lump-sum taxes decuple the government's decision of which $i$ to offer from its decision of which $\gamma$ to choose. To replicate the allocation of the inside bonds economy for a given $\gamma$ it simply sets $i=(\gamma-\beta) / \beta$. With this policy no buyer is constraint in the bonds market and so $\varepsilon u^{\prime}\left(q_{\varepsilon}\right)=1+i$ for all $\varepsilon$.

This shows that the key friction responsible for the different allocations at low inflation rates is the lack of enforcement. The proposition is related to the findings of Kocherlakota (2007). The difference is that in our model money has an essential role in transactions while in Kocherlakota money is not a medium of exchange. Finally, note that with enforcement the Friedman rule $\gamma=\beta$ is optimal in both economies.

\section{Conclusion}

When agents are liquidity constrained, two options exist to relax this constraint: sell assets or issue debt. We have analyzed and compared the welfare properties of these two options in a model where agents can either issue nominal inside bonds or sell nominal outside bonds. The key assumption of

\footnotetext{
${ }^{22}$ See Berentsen Camera and Waller (2007) for the derivation.
} 
our analysis is the absence of collection powers by private agents and the government. The following results emerged from our analysis. First, for any positive inflation rate, bonds are essential in both economies, and thus generate societal benefits. Second, we showed that for sufficiently high inflation rates, the allocations in the two economies are the same, but they differ for low inflation rates. Third, any allocation attained in the economy with inside bonds can be replicated in the economy with outside bonds. The converse is not true. Finally, under the optimal policies, the optimal allocation with illiquid outside bonds dominates the allocation with inside bonds. We also showed that the key friction which is responsible for theses two mechanisms to yield different allocations is enforcement. If the private sector can enforce repayment of debt and if the government can levy lump-sum taxes, then given an equilibrium in one of these economies, it is possible to pick policy in the other economy that generates an outcome-equivalent equilibrium. 


\section{Appendix}

Proof of Proposition 1. Consider $\gamma<\bar{\gamma}$. From (21) define

$$
f(\tilde{\varepsilon}) \equiv(1-n) \frac{1}{\tilde{\varepsilon}} \int_{\tilde{\varepsilon}}^{\varepsilon_{H}} \varepsilon d F(\varepsilon)-(1-n) \int_{\tilde{\varepsilon}}^{\varepsilon_{H}} d F(\varepsilon)
$$

We have $f^{\prime}(\tilde{\varepsilon})<0$ with $\lim _{\tilde{\varepsilon} \rightarrow 0} f(\tilde{\varepsilon})=+\infty$ and $f\left(\varepsilon_{H}\right)=0$. Consequently, if $\gamma \leq \gamma_{H}$, then a unique $0<\tilde{\varepsilon} \leq \varepsilon_{H}$ solves (21). If $\bar{\gamma}>\gamma>\gamma_{H}$, we have $\tilde{\varepsilon}>\varepsilon_{H}$ and

$$
q_{\varepsilon}=u^{\prime-1}\left(\frac{\gamma}{\varepsilon\left[1+(1-\gamma) M_{0} / B_{0}\right]}\right)
$$

for all $\varepsilon$.

Proof of Proposition 2. The policy choices are $\gamma$ and $B_{0} / M_{0}$. However, for the proof it is more convenient to define $\Theta \equiv 1-(\gamma-1) M_{0} / B_{0}$ and rewrite (20) and (21) as follows.

$$
\begin{aligned}
\tilde{\varepsilon} u^{\prime}(\tilde{q}) & =\frac{1+(1-\Theta) B_{0} / M_{0}}{\Theta} \\
\Theta & =\beta\left[(1-n) \int_{\tilde{\varepsilon}}^{\varepsilon_{H}}\left(\frac{\varepsilon}{\tilde{\varepsilon}}-1\right) d F(\varepsilon)+1\right]
\end{aligned}
$$

In the following, we consider choices of $\Theta$ and $B_{0} / M_{0}$. With this formulation, a change in $B_{0} / M_{0}$ has no effect on the extensive margin as (42) is independent of $B_{0} / M_{0}$.

We now show which values of $\Theta$ are consistent with an equilibrium where agents hold positive amounts of bonds and money. From (41), any equilibrium requires that $\frac{1+(1-\Theta) B_{0} / M_{0}}{\Theta} \geq 1$ implying $0<\Theta \leq 1$. From (42) we have $\beta \leq \Theta$ since $(1-n) \int_{\tilde{\varepsilon}}^{\varepsilon_{H}}\left(\frac{\varepsilon}{\tilde{\varepsilon}}-1\right) d F(\varepsilon) \geq 0$ in any equilibrium. The admissible values are therefore $\beta \leq \Theta \leq 1$.

The remainder of the proof involves two steps. We first show that for any admissible $\beta \leq \Theta \leq 1$ it is optimal to let $B_{0} / M_{0} \rightarrow 0$. We then show that, if $B_{0} / M_{0}$ is sufficiently small, it is optimal to choose $\Theta=\beta$.

First step. From (42), if $\Theta$ is constant then $\tilde{\varepsilon}$ is constant. Assume $\Theta=1$. Then, $\tilde{\varepsilon} u^{\prime}(\tilde{q})=1$ and $1 / \beta=(1-n) \int_{\tilde{\varepsilon}}^{\varepsilon_{H}}\left(\frac{\varepsilon}{\tilde{\varepsilon}}-1\right) d F(\varepsilon)+1$. In this case, $B_{0} / M_{0}$ has no effect on the allocation. So a best policy is to let $B_{0} / M_{0} \rightarrow 0$. Assume next $\beta \leq \Theta<1$. Then, since $\tilde{\varepsilon}$ is constant, from (41), $d \tilde{q} / d\left(B_{0} / M_{0}\right)<0$, and so it is optimal to let $B_{0} / M_{0} \rightarrow 0$. Note that for $B_{0} / M_{0} \rightarrow 0$ we obtain 
$\tilde{\varepsilon} u^{\prime}(\tilde{q})=1 / \Theta \in[1,1 / \beta]$ and

$$
\frac{\Theta}{\beta}=\left[(1-n) \int_{\tilde{\varepsilon}}^{\varepsilon_{H}}\left(\frac{\varepsilon}{\tilde{\varepsilon}}-1\right) d F(\varepsilon)+1\right] \in[1,1 / \beta]
$$

since $\beta \leq \Theta \leq 1$.

Second step. Let us now assume that $B_{0} / M_{0} \in(0, \varphi]$ with $\varphi \rightarrow 0$, i.e., small but strictly positive. To choose $\Theta$ optimally, totally differentiate (41) and (42), while holding $B_{0} / M_{0}$ constant, to get

$$
1+\beta(1-n) \frac{1}{\tilde{\varepsilon} \Theta} \int_{\tilde{\varepsilon}}^{\varepsilon_{H}} \varepsilon d F(\varepsilon) \frac{d \tilde{\varepsilon}}{d \Theta} \frac{\Theta}{\tilde{\varepsilon}}=0
$$

Substitute $\frac{d \tilde{\varepsilon}}{d \Theta} \frac{\Theta}{\tilde{\varepsilon}}$ to get

$$
1-\frac{1}{\beta(1-n) \frac{1}{\tilde{\varepsilon} \Theta} \int_{\tilde{\varepsilon}}^{\varepsilon} \varepsilon_{H} d F(\varepsilon)}+\frac{B_{0} / M_{0}}{\tilde{\varepsilon} u^{\prime}(\tilde{q})}=-\frac{u^{\prime \prime}(\tilde{q}) \tilde{q}}{u^{\prime}(\tilde{q})} \frac{d \tilde{q}}{d \Theta} \frac{\Theta}{\tilde{q}}
$$

Since $\frac{u^{\prime \prime}(\tilde{q}) \tilde{q}}{u^{\prime}(\tilde{q})}<0, \frac{d \tilde{q}}{d \Theta}<0$ if the left-hand side is negative, i.e., if

$$
(1-n) \int_{\tilde{\varepsilon}}^{\varepsilon_{H}}(\varepsilon / \tilde{\varepsilon}) d F(\varepsilon)\left[1+\frac{B_{0} / M_{0}}{\tilde{\varepsilon} u^{\prime}(\tilde{q})}\right]<\Theta / \beta
$$

Use (42) to replace the right-hand side

$$
(1-n) \int_{\tilde{\varepsilon}}^{\varepsilon_{H}} \frac{\varepsilon}{\tilde{\varepsilon}} d F(\varepsilon)\left[\frac{\Theta B_{0} / M_{0}}{1+(1-\Theta) B_{0} / M_{0}}\right]<1-(1-n) \int_{\tilde{\varepsilon}}^{\varepsilon_{H}} d F(\varepsilon)
$$

which is true for small $B_{0} / M_{0}$. We, therefore, have established that $\frac{d \tilde{q}}{d \Theta}<0$ if $B_{0} / M_{0}$ is small. Since $\frac{d \tilde{\varepsilon}}{d \Theta}<0$ and $\frac{d \tilde{q}}{d \Theta}<0$, it is optimal to choose $\Theta=\beta$.

The optimal policy is therefore to set $\gamma=1+(1-\beta) B_{0} / M_{0}$ and then let $B_{0} / M_{0} \rightarrow 0$. From (20) and (21) this implies that $\tilde{\varepsilon} u^{\prime}(\tilde{q})=1 / \beta$ and $\tilde{\varepsilon}=\varepsilon_{H}$. Finally, from (13), we get $\varepsilon u^{\prime}\left(q_{\varepsilon}\right)=1 / \beta$ $\forall \varepsilon$.

Proof of Lemma 1. Consider a borrower who borrowed $-\bar{b}$ in market 1 and is considering defaulting on his issued bonds in market 3. The real borrowing constraint $\bar{\ell}=\phi \bar{b}$ satisfies $V(m, b)=$ $\widehat{V}(m, b)$. If he redeems his bonds, he gets the equilibrium expected discounted utility in a steady 
state

$$
V(m, b)=U\left(x^{*}\right)-h_{\varepsilon}+\frac{\beta}{1-\beta}\left\{\int_{0}^{\varepsilon_{H}}\left[(1-n) \varepsilon u\left(q_{\varepsilon}\right)-n q_{s}\right] d F(\varepsilon)+U\left(x^{*}\right)-h\right\}
$$

where $h_{\varepsilon}$ is his production in market 3 if he repays his loan. Since $\widehat{x}=x^{*}$ a defaulter's expected discounted utility is

$$
\widehat{V}(m, b)=U(\widehat{x})-\widehat{h}_{\varepsilon}+\frac{\beta}{1-\beta}\left\{\int_{0}^{\varepsilon_{H}}\left[(1-n) \varepsilon u\left(\widehat{q}_{\varepsilon}\right)-n \widehat{q}_{s}\right] d F(\varepsilon)+U\left(x^{*}\right)-\widehat{h}\right\}
$$

It then follows that $V(m, b)=\widehat{V}(m, b)$ requires

$$
h_{\varepsilon}-\widehat{h}_{\varepsilon}=\frac{\beta}{1-\beta}\left[(1-n) \Psi\left(q_{\varepsilon}, \widehat{q}_{\varepsilon}\right)+\widehat{h}-h\right] .
$$

where $\Psi\left(q_{\varepsilon}, \widehat{q}_{\varepsilon}\right)=\int_{0}^{\varepsilon_{H}}\left[\varepsilon u\left(q_{\varepsilon}\right)-q_{\varepsilon}\right] d F(\varepsilon)-\int_{0}^{\varepsilon_{H}}\left[\varepsilon u\left(\widehat{q}_{\varepsilon}\right)-\widehat{q}_{\varepsilon}\right] d F(\varepsilon)>0$. We get this expression for $\Psi\left(q_{\varepsilon}, \widehat{q}_{\varepsilon}\right)$, because sellers are indifferent as to how much they produce and we, therefore, assume that the deviator produces $\hat{q}_{s}=\left(\frac{1-n}{n}\right) \int_{\varepsilon_{L}}^{\varepsilon_{H}} \widehat{q}_{\varepsilon} d F(\varepsilon)$ in the decentralized market in each period. Furthermore, from market clearing we have $n q_{s}=(1-n) \int_{0}^{\varepsilon_{H}} q_{\varepsilon} d F(\varepsilon)$.

Deriving $h_{\varepsilon}-\widehat{h}_{\varepsilon}$ : If the buyer redeems his bonds, he works

$$
\begin{aligned}
h_{\varepsilon} & =x^{*}+\phi m_{1,+1}-\phi\left[m_{1}+\bar{b}-p q_{\varepsilon}\right]-\phi \tau M_{-1}+\phi \bar{b}(1+i) \\
& =x^{*}+\phi m_{1,+1}-\phi\left[m_{1}-p q_{\varepsilon}\right]-\phi \tau M_{-1}+\phi \bar{b} i \\
& =x^{*}+q_{\varepsilon}+\bar{\ell} i
\end{aligned}
$$

where we use the equilibrium condition $m_{1,+1}=m_{1}+\tau M_{-1}=\gamma m_{1}$. If he defaults on his bonds, he works

$$
\begin{aligned}
\widehat{h}_{\varepsilon} & =x^{*}+\phi \widehat{m}_{1,+1}-\phi\left[m_{1}+\bar{b}-p q_{\varepsilon}\right]-\phi \tau M_{-1} \\
& =x^{*}+\phi\left(\widehat{m}_{1,+1}-m_{1,+1}\right)-\bar{\ell}+q_{\varepsilon} \\
& =x^{*}+\phi \gamma\left(\widehat{m}_{1}-m_{1}\right)-\bar{\ell}+q_{\varepsilon}
\end{aligned}
$$


where we use the fact that a defaulter's money balances grows at the rate $\gamma$ so $\widehat{m}_{1,+1}=\gamma \widehat{m}_{1}$. Thus

$$
h_{\varepsilon}-\widehat{h}_{\varepsilon}=(1+i) \bar{\ell}-\phi \gamma\left(\widehat{m}_{1}-m_{1}\right)
$$

Deriving $\widehat{h}-h$ : Once the agent defaults, as a buyer he spent $p \widehat{q}_{\varepsilon}$ units of money so his hours worked are

$$
\begin{aligned}
\widehat{h}_{\varepsilon} & =x^{*}+\phi \hat{m}_{1,+1}-\phi\left(\widehat{m}_{1}-p \widehat{q}_{\varepsilon}\right)-\phi \tau M_{-1} \\
& =x^{*}+\phi\left(\widehat{m}_{1,+1}-\widehat{m}_{1}\right)+\phi p \widehat{q}_{\varepsilon}-\phi\left(m_{1,+1}-m_{1}\right) \\
& =x^{*}+(\gamma-1) \phi\left(\widehat{m}_{1}-m_{1}\right)+\phi p \widehat{q}_{\varepsilon}
\end{aligned}
$$

For a seller, we have

$$
\begin{aligned}
\widehat{h}_{s} & =x^{*}+\phi \widehat{m}_{1,+1}-\phi\left(\widehat{m}_{1}+p \widehat{q}_{s}\right)-\phi \tau M_{-1} \\
& =x^{*}+(\gamma-1) \phi\left(\widehat{m}_{1}-m_{1}\right)-\phi p\left(\frac{1-n}{n}\right) \int_{0}^{\varepsilon_{H}} \widehat{q}_{\varepsilon} d F(\varepsilon)
\end{aligned}
$$

A defaulter's expected hours worked are therefore

$$
\widehat{h}=(1-n) \widehat{h}_{\varepsilon}+n \widehat{h}_{s}=x^{*}+(\gamma-1) \phi\left(\widehat{m}_{1}-m_{1}\right)
$$

while, if he does not deviate, he works $h=x^{*}$ and so

$$
\widehat{h}-h=(\gamma-1) \phi\left(\widehat{m}_{1}-m_{1}\right)
$$

Solving for $\bar{\ell}$ : Using (44)-(46) we get

$$
\bar{\ell}=\frac{\beta}{(1-\beta)(1+i)}\left[(1-n) \Psi\left(q_{\varepsilon}, \widehat{q}_{\varepsilon}\right)+\left(\frac{\gamma-\beta}{\beta}\right)\left(\phi \widehat{m}_{1}-\phi m_{1}\right)\right]
$$

In equilibrium $\phi \widehat{m}_{1}=\widehat{q}$, and using market clearing $\phi m_{1}=\phi M_{-1}=Q \equiv(1-n) \int_{0}^{\varepsilon_{H}} q_{\varepsilon} d F(\varepsilon)$. So we have

$$
\bar{\ell}=\frac{\beta}{(1-\beta)(1+i)}\left[(1-n) \Psi\left(q_{\varepsilon}, \widehat{q}_{\varepsilon}\right)+\left(\frac{\gamma-\beta}{\beta}\right)(\widehat{q}-Q)\right]
$$


To know whether $\bar{\ell}>0$, we need to determine the sign of right-hand side. Substituting for $\Psi\left(q_{\varepsilon}, \widehat{q}_{\varepsilon}\right)$ and $Q$ we need

$$
\begin{gathered}
(1-n) \int_{0}^{\varepsilon_{H}}\left[\varepsilon u\left(q_{\varepsilon}\right)-q_{\varepsilon}\right] d F(\varepsilon)-(1-n) \int_{0}^{\varepsilon_{H}}\left[\varepsilon u\left(\widehat{q}_{\varepsilon}\right)-\widehat{q}_{\varepsilon}\right] d F(\varepsilon)+ \\
\left(\frac{\gamma-\beta}{\beta}\right)\left[\widehat{q}-(1-n) \int_{0}^{\varepsilon_{H}} q_{\varepsilon} d F(\varepsilon)\right]>0
\end{gathered}
$$

We have

$$
\frac{\gamma-\beta}{\beta}=(1-n) \int_{0}^{\varepsilon_{H}}\left[\varepsilon u^{\prime}\left(\widehat{q}_{\varepsilon}\right)-1\right] d F(\varepsilon)
$$

Substituting the right-hand side, we get

$$
\begin{aligned}
& \int_{0}^{\varepsilon_{H}}\left[\varepsilon u\left(q_{\varepsilon}\right)-q_{\varepsilon}\right] d F(\varepsilon)-\int_{0}^{\varepsilon_{H}}\left[\varepsilon u\left(\widehat{q}_{\varepsilon}\right)-\widehat{q}_{\varepsilon}\right] d F(\varepsilon) \\
+ & \int_{0}^{\varepsilon_{H}}\left[\varepsilon u^{\prime}\left(\widehat{q}_{\varepsilon}\right)-1\right] d F(\varepsilon)\left[\widehat{q}-(1-n) \int_{0}^{\varepsilon_{H}} q_{\varepsilon} d F(\varepsilon)\right]>0
\end{aligned}
$$

In an unconstrained borrowing equilibrium we have

$$
\frac{\gamma-\beta}{\beta}=\int_{0}^{\varepsilon_{H}}\left[\varepsilon u^{\prime}\left(q_{\varepsilon}\right)-1\right] d F(\varepsilon)
$$

So (47) and (48) yield

$$
1-n=\frac{\int_{0}^{\varepsilon_{H}}\left[\varepsilon u^{\prime}\left(q_{\varepsilon}\right)-1\right] d F(\varepsilon)}{\int_{0}^{\varepsilon_{H}}\left[\varepsilon u^{\prime}\left(\widehat{q}_{\varepsilon}\right)-1\right] d F(\varepsilon)}<1
$$

Substitute this in

$$
\begin{gathered}
\int_{0}^{\varepsilon_{H}}\left[\varepsilon u\left(q_{\varepsilon}\right)-q_{\varepsilon}\right] d F(\varepsilon)-\int_{0}^{\varepsilon_{H}}\left[\varepsilon u\left(\widehat{q}_{\varepsilon}\right)-\widehat{q}_{\varepsilon}\right] d F(\varepsilon) \\
+\int_{0}^{\varepsilon_{H}}\left[\varepsilon u^{\prime}\left(\widehat{q}_{\varepsilon}\right)-1\right] d F(\varepsilon)\left[\widehat{q}-\frac{\int_{0}^{\varepsilon_{H}}\left[\varepsilon u^{\prime}\left(q_{\varepsilon}\right)-1\right] d F(\varepsilon)}{\int_{0}^{\varepsilon_{H}}\left[\varepsilon u^{\prime}\left(\widehat{q}_{\varepsilon}\right)-1\right] d F(\varepsilon)} \int_{0}^{\varepsilon_{H}} q_{\varepsilon} d F(\varepsilon)\right]>0 \\
\int_{0}^{\varepsilon_{H}}\left[\varepsilon u\left(q_{\varepsilon}\right)-q_{\varepsilon}\right] d F(\varepsilon)-\int_{0}^{\varepsilon_{H}}\left[\varepsilon u\left(\widehat{q}_{\varepsilon}\right)-\widehat{q}_{\varepsilon}\right] d F(\varepsilon) \\
+\widehat{q} \int_{0}^{\varepsilon_{H}}\left[\varepsilon u^{\prime}\left(\widehat{q}_{\varepsilon}\right)-1\right] d F(\varepsilon)-\int_{0}^{\varepsilon_{H}} q_{\varepsilon} d F(\varepsilon) \int_{0}^{\varepsilon_{H}}\left[\varepsilon u^{\prime}\left(q_{\varepsilon}\right)-1\right] d F(\varepsilon)>0
\end{gathered}
$$


Rewrite as

$$
\begin{aligned}
& \int_{0}^{\varepsilon_{H}}\left[\varepsilon u\left(q_{\varepsilon}\right)-q_{\varepsilon}\right] d F(\varepsilon)-\int_{0}^{\varepsilon_{H}}\left[\varepsilon u\left(\widehat{q}_{\varepsilon}\right)-\widehat{q}_{\varepsilon}\right] d F(\varepsilon) \\
> & \int_{0}^{\varepsilon_{H}} q_{\varepsilon} d F(\varepsilon) \int_{0}^{\varepsilon_{H}}\left[\varepsilon u^{\prime}\left(q_{\varepsilon}\right)-1\right] d F(\varepsilon)-\widehat{q} \int_{0}^{\varepsilon_{H}}\left[\varepsilon u^{\prime}\left(\widehat{q}_{\varepsilon}\right)-1\right] d F(\varepsilon)
\end{aligned}
$$

Divide both sides by $\int_{0}^{\varepsilon_{H}} q_{\varepsilon} d F(\varepsilon)-\int_{0}^{\varepsilon_{H}} \widehat{q}_{\varepsilon} d F(\varepsilon)$ to get

$$
\begin{aligned}
& \frac{\int_{0}^{\varepsilon_{H}}\left[\varepsilon u\left(q_{\varepsilon}\right)-q_{\varepsilon}\right] d F(\varepsilon)-\int_{0}^{\varepsilon_{H}}\left[\varepsilon u\left(\widehat{q}_{\varepsilon}\right)-\widehat{q}_{\varepsilon}\right] d F(\varepsilon)}{\int_{0}^{\varepsilon_{H}} q_{\varepsilon} d F(\varepsilon)-\int_{0}^{\varepsilon_{H}} \widehat{q}_{\varepsilon} d F(\varepsilon)} \\
> & \int_{0}^{\varepsilon_{H}}\left[\varepsilon u^{\prime}\left(q_{\varepsilon}\right)-1\right] d F(\varepsilon) \frac{\int_{0}^{\varepsilon_{H}} q_{\varepsilon} d F(\varepsilon)-\widehat{q} \frac{\int_{0}^{\varepsilon_{H}}\left[\varepsilon u^{\prime}\left(\widehat{q}_{\varepsilon}\right)-1\right] d F(\varepsilon)}{\int_{0}^{\varepsilon_{H}}\left[\varepsilon u^{\prime}\left(q_{\varepsilon}\right)-1\right] d F(\varepsilon)}}{\int_{0}^{\varepsilon_{H}} q_{\varepsilon} d F(\varepsilon)-\int_{0}^{\varepsilon_{H}} \widehat{q}_{\varepsilon} d F(\varepsilon)}
\end{aligned}
$$

which always holds because the LHS is greater than $\int_{0}^{\varepsilon_{H}}\left[\varepsilon u^{\prime}\left(q_{\varepsilon}\right)-1\right] d F(\varepsilon)$ and

$$
\frac{\int_{0}^{\varepsilon_{H}} q_{\varepsilon} d F(\varepsilon)-\widehat{q} \frac{\int_{0}^{\varepsilon_{H}}\left[\varepsilon u^{\prime}\left(\widehat{q}_{\varepsilon}\right)-1\right] d F(\varepsilon)}{\int_{0}^{\varepsilon}\left[\varepsilon u^{\prime}\left(q_{\varepsilon}\right)-1\right] d F(\varepsilon)}}{\int_{0}^{\varepsilon_{H}} q_{\varepsilon} d F(\varepsilon)-\int_{0}^{\varepsilon_{H}} \widehat{q}_{\varepsilon} d F(\varepsilon)}<1
$$

So $\bar{\ell}>0$ in an unconstrained equilibrium.

Proof of Proposition 3. In an unconstrained equilibrium we have unique values for $q_{\varepsilon}$ and $i=(\gamma-\beta) / \beta$. All that is left is to show that $\ell_{H} \leq \bar{\ell}$ or

$$
\ell_{H} \leq \frac{\beta}{(1-\beta)(1+i)}(1-n) \Psi\left(q_{\varepsilon}, \widehat{q}_{\varepsilon}\right)+\frac{\beta i(\widehat{q}-Q)}{(1-\beta)(1+i)}
$$

Since all agents (including the one with $\varepsilon_{H}$ ) are unconstrained, we have $\ell_{H}=q_{\varepsilon_{H}}-\phi M_{-1}$ and $\phi M_{-1}=Q$ so that we have

$$
(1-\beta)(1+i)\left(q_{\varepsilon_{H}}-Q\right) \leq \beta(1-n) \Psi\left(q_{\varepsilon}, \widehat{q}_{\varepsilon}\right)+i \beta(\widehat{q}-Q)
$$

Define

$$
\Delta(i, \beta) \equiv(1-\beta)(1+i)\left(q_{\varepsilon_{H}}-Q\right)-\beta(1-n) \Psi\left(q_{\varepsilon}, \widehat{q}_{\varepsilon}\right)-i \beta(\widehat{q}-Q)
$$

So we need $\Delta(i, \beta) \leq 0$ in an unconstrained borrowing equilibrium. Note that $\Delta(0, \beta)=(1-\beta)\left(q_{\varepsilon_{H}}^{*}-Q^{*}\right)>$ 0 , since $\Psi\left(q_{\varepsilon}^{*}, \widehat{q}_{\varepsilon}^{*}\right)=0$ at $i=0$. Thus, (49) is violated at the Friedman rule. 
Consider solutions to $\Delta(i, \beta)=0$. Note that $\Delta(0,1)=0$, since $\left.q_{\varepsilon}\right|_{(0,1)}=\left.\widehat{q}_{\varepsilon}\right|_{(0,1)}=q_{\varepsilon}^{*}$ and $\Psi\left(q_{\varepsilon}^{*}, \widehat{q}_{\varepsilon}^{*}\right)=0$. Let $\Delta_{i}(i, \beta) \equiv \frac{\partial \Delta(i, \beta)}{\partial i}$. Then, we have

$$
\begin{aligned}
\Delta_{i}(i, \beta)= & (1-\beta)\left(q_{\varepsilon_{H}}-Q\right)+(1-\beta)(1+i)\left(\frac{\partial q_{\varepsilon_{H}}}{\partial i}-\frac{\partial Q}{\partial i}\right) \\
& -\beta(1-n) \frac{\partial \Psi\left(q_{\varepsilon}, \widehat{q}_{\varepsilon}\right)}{\partial i}-\beta(\widehat{q}-Q)-\beta i\left(\frac{\partial \widehat{q}}{\partial i}-\frac{\partial Q}{\partial i}\right)
\end{aligned}
$$

Since the partial derivatives in this expression are all continuous, $\Delta_{i}(i, \beta)$ is continuous and nonzero with

$$
\Delta_{i}(0,1)=-\left.\beta(\widehat{q}-Q)\right|_{(0,1)}=-\left[q_{\varepsilon_{H}}^{*}-(1-n) \int_{0}^{\varepsilon_{H}} q_{\varepsilon}^{*} d F(\varepsilon)\right]<0
$$

since $\left.\frac{\partial \Psi\left(q_{\varepsilon}, \widehat{q}_{\varepsilon}\right)}{\partial i}\right|_{(0,1)}=0$ and $\left.\widehat{q}\right|_{(0,1)}=q_{\varepsilon_{H}}^{*}$.

Let $\Delta_{\beta}(i, \beta) \equiv \frac{\partial \Delta(i, \beta)}{\partial \beta}$. Then, we have

$$
\begin{aligned}
\Delta_{\beta}(i, \beta)= & -(1+i)\left(q_{\varepsilon_{H}}-Q\right)+(1-\beta)(1+i)\left(\frac{\partial q_{\varepsilon_{H}}}{\partial \beta}-\frac{\partial Q}{\partial \beta}\right) \\
& -(1-n) \Psi\left(q_{\varepsilon}, \widehat{q}_{\varepsilon}\right)-\beta(1-n) \frac{\partial \Psi\left(q_{\varepsilon}, \widehat{q}_{\varepsilon}\right)}{\partial \beta}-i(\widehat{q}-Q)-i \beta\left(\frac{\partial \widehat{q}}{\partial \beta}-\frac{\partial Q}{\partial \beta}\right)
\end{aligned}
$$

Therefore $\Delta_{\beta}(0,1)$ is continuous and

$$
\Delta_{\beta}(0,1)=-\left[q_{\varepsilon_{H}}^{*}-(1-n) \int_{0}^{\varepsilon_{H}} q_{\varepsilon}^{*} d F(\varepsilon)\right]<0 .
$$

since $\left.\frac{\partial \Psi\left(q_{\varepsilon}, \widehat{q}_{\varepsilon}\right)}{\partial \beta}\right|_{(0,1)}=0$. By the implicit function theorem, it follows that, for $\beta$ arbitrarily close to 1 , the expression $\Delta(i, \beta)=0$ defines $i$ as an implicit function of $\beta$, i.e., $i=\hat{\imath}(\beta)$.

Furthermore, we have

$$
\left.\frac{d i}{d \beta}\right|_{(0,1)}=-\frac{\Delta_{\beta}(0,1)}{\Delta_{i}(0,1)}=-1,
$$

so that as $\beta$ falls, $i$ grows. It follows from the implicit function theorem that $\Delta(\hat{\imath}, \beta)=0$ for a unique $\hat{\imath}>0$, and $\beta$ sufficiently close to 1 .

Establishing the existence and uniqueness of the unconstrained credit equilibrium for $i>\hat{\imath}$. Above, we established that $\Delta(0, \beta)>0$ for all $0<\beta<1$. Fix $\beta$ close to 1 . We have established that $\Delta(\hat{\imath}, \beta)=0$ for some $\hat{\imath}>0$. By continuity of $\Delta(\hat{\imath}, \beta)$, if $i>\hat{\imath}$, then $\Delta(0, \beta)<0$, and so an unconstrained equilibrium exists. For $0 \leq i<\hat{\imath}$, then $\Delta(i, \beta) \geq 0$ which violates (49). This 
establishes the first part of Proposition 3.

Consider $0 \leq i<\hat{\imath}$. In general, we cannot prove existence or uniqueness. We now characterize the properties of (32) and (36)-(38). At $i=0,(37)-(38)$ imply $\tilde{\varepsilon}=\hat{\varepsilon}$ so $\tilde{q}=\widehat{q}$ and $\Psi\left(q_{\varepsilon}, \widehat{q}_{\varepsilon}\right)=0$. Then from (32) and (36) we have $\gamma=1$. This implies there is one and only one monetary policy consistent with a nominal interest rate of zero and also satisfies (36). Thus, a monetary equilibrium with credit does not exist at $\gamma=1$.

Furthermore, we have

$$
\left.\frac{d i}{d \gamma}\right|_{\gamma=1}=\frac{1}{1-\beta}>0
$$

To obtain this, use (36) to replace $\bar{\ell}$ in (32) and then totally differentiate the resulting expression:

$$
\begin{gathered}
(\tilde{q}-Q)(1+i)=\frac{\beta(1-n)}{1-\beta} \Psi\left(q_{\varepsilon}, \widehat{q}_{\varepsilon}\right)+\left(\frac{\gamma-\beta}{1-\beta}\right)(\widehat{q}-Q) \\
(1+i)(d \tilde{q}-d Q)+(\tilde{q}-Q) d i \\
=\frac{\beta(1-n)}{1-\beta}\left\{\left[\int_{0}^{\varepsilon_{H}} \varepsilon u^{\prime}\left(q_{\varepsilon}\right) d q_{\varepsilon}-d q_{\varepsilon}\right] d F(\varepsilon)-\left[\int_{0}^{\varepsilon_{H}} \varepsilon u^{\prime}\left(\hat{q}_{\varepsilon}\right) d \widehat{q}_{\varepsilon}-d \widehat{q}_{\varepsilon}\right] d F(\varepsilon)\right\} \\
+\frac{\beta}{1-\beta}\left[\left(\frac{\gamma-\beta}{\beta}\right)(d \widehat{q}-d Q)+\frac{1}{\beta}(\widehat{q}-Q) d \gamma\right]
\end{gathered}
$$

Evaluate at $i=0$ and $\gamma=1$ to get

$$
\begin{aligned}
& (d \tilde{q}-d Q)+(\tilde{q}-Q) d i \\
= & \frac{\beta(1-n)}{1-\beta}\left\{\left[\int_{\tilde{\varepsilon}}^{\varepsilon_{H}} \varepsilon u^{\prime}\left(q_{\varepsilon}\right)-1\right] d F(\varepsilon) d \tilde{q}-\left[\int_{\hat{\varepsilon}}^{\varepsilon_{H}} \varepsilon u^{\prime}\left(\hat{q}_{\varepsilon}\right)-1\right] d F(\varepsilon) d \widehat{q}\right\} \\
& +\frac{\beta}{1-\beta}\left[\left(\frac{\gamma-\beta}{\beta}\right)(d \widehat{q}-d Q)+\frac{1}{\beta}(\widehat{q}-Q) d \gamma\right]
\end{aligned}
$$

Note $\left[\int_{\tilde{\varepsilon}}^{\varepsilon_{H}} \varepsilon u^{\prime}\left(q_{\varepsilon}\right)-1\right] d F(\varepsilon)=\left[\int_{\hat{\varepsilon}}^{\varepsilon_{H}} \varepsilon u^{\prime}\left(\hat{q}_{\varepsilon}\right)-1\right] d F(\varepsilon)=\frac{1-\beta}{\beta}$ and use $\tilde{q}=\widehat{q}$ and (37)-(38) to get

$$
\begin{aligned}
d \tilde{q}-d Q+(\widehat{q}-Q) d i= & \frac{\beta}{1-\beta}\left(\frac{1-\beta}{\beta} d \tilde{q}-\frac{1-\beta}{\beta} d \widehat{q}\right) \\
& +\frac{\beta}{1-\beta}\left[\left(\frac{1-\beta}{\beta}\right)(d \widehat{q}-d Q)+\frac{1}{\beta}(\widehat{q}-Q) d \gamma\right]
\end{aligned}
$$

This expression reduces to (50). 
Proof of Proposition 4. In equilibrium, welfare is given by (1). Again, using (2) differentiate (1) with respect to $\gamma$ to get

$$
\left.(1-\beta) \frac{d \mathcal{W}}{d \gamma}\right|_{\gamma=1}=\left.(1-n) \int_{0}^{\varepsilon_{H}}\left[\varepsilon u^{\prime}\left(q_{\varepsilon}\right)-1\right] \frac{d q_{\varepsilon}}{d \gamma}\right|_{\gamma=1} d F(\varepsilon)>0
$$

Since $\varepsilon u^{\prime}\left(q_{\varepsilon}\right)-1=0$ for all $\varepsilon \leq \tilde{\varepsilon}$ at $\gamma=1$, and $q_{\varepsilon}=\tilde{q}$ for all $\varepsilon \geq \tilde{\varepsilon}$, welfare will be increasing in $\gamma$ if $\left.\frac{d \tilde{q}}{d \gamma}\right|_{\gamma=1}>0$.

Using $\varepsilon u^{\prime}\left(q_{\varepsilon}\right)=1+i$ for all $\varepsilon \leq \tilde{\varepsilon}$ and $q_{\varepsilon}=\tilde{q}$ for all $\varepsilon \geq \tilde{\varepsilon}$ (28) can be written as

$$
\frac{\gamma-\beta}{\beta}=(1-n) u^{\prime}(\tilde{q}) \int_{\tilde{\varepsilon}}^{\varepsilon_{H}} \varepsilon d F(\varepsilon)+(1-n)(1+i) \int_{0}^{\tilde{\varepsilon}} d F(\varepsilon)-1+n+n i
$$

Totally differentiate (51):

$$
\begin{aligned}
\frac{1}{\beta} d \gamma= & (1-n) u^{\prime \prime}(\tilde{q}) d \tilde{q} \int_{\tilde{\varepsilon}}^{\varepsilon_{H}} \varepsilon d F(\varepsilon)-(1-n)\left[\tilde{\varepsilon} u^{\prime}(\tilde{q})-(1+i)\right] d F(\tilde{\varepsilon}) d \tilde{\varepsilon} \\
& +\left[n+(1-n) \int_{0}^{\tilde{\varepsilon}} d F(\varepsilon)\right] d i
\end{aligned}
$$

Using $\tilde{\varepsilon} u^{\prime}(\tilde{q})=1+i$, we have

$$
\frac{1}{\beta} d \gamma=(1-n) u^{\prime \prime}(\tilde{q}) d \tilde{q} \int_{\tilde{\varepsilon}}^{\varepsilon_{H}} \varepsilon d F(\varepsilon)+\left[n+(1-n) \int_{0}^{\tilde{\varepsilon}} d F(\varepsilon)\right] d i
$$

Substituting (50) into (52) gives

$$
\frac{1}{\beta} d \gamma=\left[(1-n) u^{\prime \prime}(\tilde{q}) \int_{\tilde{\varepsilon}}^{\varepsilon_{H}} \varepsilon d F(\varepsilon)\right] d \tilde{q}+\left[n+(1-n) \int_{0}^{\tilde{\varepsilon}} d F(\varepsilon)\right] \frac{1}{1-\beta} d \gamma
$$

Thus

$$
\left.\frac{d \tilde{q}}{d \gamma}\right|_{\gamma=1}=\frac{1-\beta-\beta\left[n+(1-n) \int_{0}^{\tilde{\varepsilon}} d F(\varepsilon)\right]}{\beta(1-\beta)(1-n) u^{\prime \prime}(\tilde{q}) \int_{\tilde{\varepsilon}}^{\varepsilon_{H}} \varepsilon d F(\varepsilon)}
$$

The denominator is negative. So $\left.\frac{d \tilde{q}}{d \gamma}\right|_{\gamma=1}>0$ and $\left.(1-\beta) \frac{d W}{d \gamma}\right|_{\gamma=1}>0$ if

$$
\beta>\frac{1}{1+n+(1-n) \int_{0}^{\tilde{\varepsilon}} d F(\varepsilon)}
$$


Proof of Proposition 5. Suppose the government finances interest rate payment on its outstanding stock of bonds through lump-sum taxes. Then, (4) reduces to

$$
M_{t}-M_{t-1}=\tau_{t} M_{t-1}
$$

Then, it is straightforward to show that (18) continues to hold which we replicate here for easier comparison:

$$
\frac{\gamma-\beta(1+i)}{\beta(1+i)}=(1-n) \int_{\tilde{\varepsilon}}^{\varepsilon_{H}}\left(\frac{\varepsilon}{\tilde{\varepsilon}}-1\right) d F(\varepsilon) .
$$

Then, by choosing $i=(\gamma-\beta) / \beta$ we get $\tilde{\varepsilon}=\varepsilon_{H}$ and so no buyer in constraint in the bonds market implying that $\varepsilon u^{\prime}\left(q_{\varepsilon}\right)=1+i$ for all $\varepsilon$. This policy replicates (39) and (40). 


\section{References}

[1] Aiyagari, R. and S. Williamson (2000). "Money and Dynamic Credit Arrangements with Private Information." Journal of Economic Theory 91, 248-279.

[2] Aykol, A. (2004). "Optimal Monetary Policy in an Economy with Incomplete Markets and Idiosyncratic Risk." Journal of Monetary Economics 51, 1245-1269.

[3] Berentsen, A., G. Camera and C. Waller (2005). "The Distribution of Money Balances and the Non-Neutrality of Money." International Economic Review, 46, 465-487.

[4] Berentsen, A., G. Camera and C. Waller (2007). "Money, Credit and Banking." Journal of Economic Theory, 135, 171-194.

[5] Boel, P. and G. Camera (2006). "Efficient Monetary Allocations and the Illiquidity of Bonds." Journal of Monetary Economics.

[6] Cavalcanti, R. and N. Wallace (1999a). "Inside and Outside Money as Alternative Media of Exchange." Journal of Money, Credit, and Banking, 31, 443-457.

[7] Cavalcanti, R. and N. Wallace (1999b). "A Model of Private Bank-Note Issue," Review of Economic Dynamics, 2, 104-136.

[8] Diaz, A. and Perrera-Tallo (2007). "Credit and Inflation Under Borrower's Lack of Commitment," Mimeo, University Carlos III de Madrid.

[9] Ferris L. and M. Watanabe (2007). "Collateral Secured Loans in a Monetary Economy." Mimeo, University Carlos III de Madrid.

[10] Hellwig M. (1993). "The Challenge of Monetary Theory.” European Economic Review, 37, 215242.

[11] Kehoe, T. and D. Levine (2001). "Liquidity Constrained Markets versus Debt Constrained Markets." Econometrica, 69, 575-598.

[12] Kocherlakota, N. (2003). "Societal Benefits of Illiquid Bonds." Journal of Economic Theory, 108, 179-193. 
[13] Kocherlakota, N. (2008). "Money and Bonds: An Equivalence Theorem." Mimeo, University of Minnesota.

[14] Lagos, R. and G. Rocheteau (2003). "On the Coexistence of Money and Other Assets." Mimeo, Federal Reserve Bank of Cleveland.

[15] Lagos, R. and G. Rocheteau (2005). "Inflation, Output and Welfare." International Economic Review, 46, 495-522.

[16] Lagos, R. and R. Wright (2005). "A Unified Framework for Monetary Theory and Policy Evaluation." Journal of Political Economy, 113, 463-484.

[17] Marchesiani, A. and P. Senesi (2007). "Money and Nominal Bonds." Mimeo, University of Naples L'Orientale.

[18] Rocheteau, G. and R. Wright (2004). "Money in Search Equilibrium, in Competitive equilibrium and in Competitive Search Equilibrium." Econometrica, 73, 175-202.

[19] Shi, S. (1997). "A Divisible Search Model of Fiat Money." Econometrica, 65, 75-102.

[20] Shi, S. (2005). "Nominal Bonds and Interest Rates." International Economic Review, 46, 579618.

[21] Shi, S. (2007). "Efficiency Improvement from Restricting the Liquidity of Nominal Bonds." Mimeo, University of Toronto.

[22] Sun, L. (2007). "Sustained Societal Benefit of Illiquid Bonds." Mimeo, University of Toronto.

[23] Taub, B. (1994). "Currency and Credit are Equivalent Mechanisms." International Economic Review, 35, 921-956.

[24] Telyukova, I. and R. Wright (2007). "A Model of Money and Credit, with Application to the Credit Card Debt Puzzle." Mimeo, University of Pennsylvania.

[25] Wallace, N. (1981). "A Modigliani-Miller Theorem for Open-Market Operations.” American Economic Review, 71, 267-274. 